\title{
Impact of diabetes in patients waiting for invasive cardiac procedures during COVID-19 pandemic
}

\begin{abstract}
Raúl Moreno ${ }^{1 *}$, José-Luis Díez² ${ }^{2}$ José-Antonio Diarte ${ }^{3}$, Pablo Salinas ${ }^{4}$, José María de la Torre Hernández ${ }^{5}$, Juan F. Andres-Cordón ${ }^{6}$, Ramiro Trillo ${ }^{7}$, Juan Alonso Briales ${ }^{8}$, Ignacio Amat-Santos ${ }^{9}$, Rafael Romaguera ${ }^{10}$, José-Francisco Díaz ${ }^{11}$, Beatriz Vaquerizo ${ }^{12}$, Soledad Ojeda ${ }^{13}$, Ignacio Cruz-González ${ }^{14}$, Daniel Morena-Salas ${ }^{15}$, Armando Pérez de Prado ${ }^{16}$, Fernando Sarnago ${ }^{17}$, Pilar Portero ${ }^{18}$, Alejandro Gutierrez-Barrios ${ }^{19}$, Fernando Alfonso ${ }^{20}$, Eduard Bosch ${ }^{21}$, Eduardo Pinar ${ }^{22}$, José-Ramón Ruiz-Arroyo ${ }^{23}$, Valeriano Ruiz-Quevedo ${ }^{24}$, Jesús Jiménez-Mazuecos ${ }^{25}$, Fernando Lozano ${ }^{26}$, José-Ramón Rumoroso ${ }^{27}$, Enrique Novo ${ }^{28}$, Francisco J. Irazusta ${ }^{29}$, Bruno García del Blanco ${ }^{30}$, José Moreu ${ }^{31}$, Sara M. Ballesteros-Pradas ${ }^{32}$, Araceli Frutos ${ }^{33}$, Manuel Villa ${ }^{34}$, Eduardo Alegría-Barrero ${ }^{35,36}$, Rosa Lázaro ${ }^{37}$ and Emilio Paredes ${ }^{38}$
\end{abstract}

\begin{abstract}
Background: During COVID-19 pandemic, elective invasive cardiac procedures (ICP) have been frequently cancelled or postponed. Consequences may be more evident in patients with diabetes.

Objectives: The objective was to identify the peculiarities of patients with DM among those in whom ICP were cancelled or postponed due to the COVID-19 pandemic, as well as to identify subgroups in which the influence of DM has higher impact on the clinical outcome.

Methods: We included 2,158 patients in whom an elective ICP was cancelled or postponed during COVID-19 pandemic in 37 hospitals in Spain. Among them, 700 (32.4\%) were diabetics. Patients with and without diabetes were compared.

Results: Patients with diabetes were older and had a higher prevalence of other cardiovascular risk factors, previous cardiovascular history and co-morbidities. Diabetics had a higher mortality (3.0\% vs. 1.0\%; $p=0.001)$ and cardiovascular mortality (1.9\% vs. $0.4 \% ; p=0.001)$. Differences were especially important in patients with valvular heart disease (mortality $6.9 \%$ vs $1.7 \%$ [p $<0.001]$ and cardiovascular mortality $4.9 \%$ vs $0.9 \%[p=0.002]$ in patients with and without diabetes, respectively). In the multivariable analysis, diabetes remained as an independent risk factor both for overall and cardiovascular mortality. No significant interaction was found with other clinical variables.
\end{abstract}

Conclusion: Among patients in whom an elective invasive cardiac procedure is cancelled or postponed during COVID-19 pandemic, mortality and cardiovascular mortality is higher in patients with diabetes, irrespectively on other clinical conditions. These procedures should not be cancelled in patients with diabetes.

Keywords: Diabetes, Interventional cardiology, COVID-19, Mortality, Waiting list

*Correspondence: raulmorenog@hotmail.com

1 University Hospital La Paz, idiPAZ, Paseo La Castellana 261,

28046 Madrid, Spain

Full list of author information is available at the end of the article

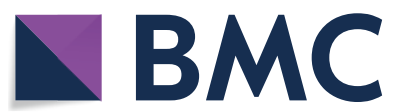

(c) The Author(s) 2021. This article is licensed under a Creative Commons Attribution 4.0 International License, which permits use, sharing, adaptation, distribution and reproduction in any medium or format, as long as you give appropriate credit to the original author(s) and the source, provide a link to the Creative Commons licence, and indicate if changes were made. The images or other third party material in this article are included in the article's Creative Commons licence, unless indicated otherwise in a credit line to the material. If material is not included in the article's Creative Commons licence and your intended use is not permitted by statutory regulation or exceeds the permitted use, you will need to obtain permission directly from the copyright holder. To view a copy of this licence, visit http://creativeco mmons.org/licenses/by/4.0/. The Creative Commons Public Domain Dedication waiver (http://creativecommons.org/publicdomain/ zero/1.0/) applies to the data made available in this article, unless otherwise stated in a credit line to the data. 


\section{Introduction}

The ongoing COVID-19 pandemic, caused by the severe acute respiratory syndrome coronavirus 2 (SARS-CoV-2), was declared by the World Health Organization (WHO) in March 2020 [1]. By January 2021, almost 100 million people had suffered the disease, and nearly 2 million have died worldwide. Apart from these direct consequences, health care systems have been severely overwhelmed, negatively impacting on the management of other patients that usually require prompt treatment, especially those with cardiovascular diseases [2-8]. Specifically, invasive cardiac procedures (ICP) have been cancelled or postponed in many centers, and this may have fatal consequences for some patients, as we have recently shown in a multicenter study from Spain [9].

Cardiovascular diseases constitute the main cause of death in patients with diabetes mellitus (DM) [10], and among patients with cardiovascular diseases, those with DM are at an especially high risk of death [11, 12]. Because of that, waiting list in patients pending on cardiovascular procedures that have been postponed due to the pandemic may have especial impact among diabetics [9].

The objective was to identify the peculiarities of patients with DM among those in whom ICP were cancelled or postponed due to the COVID-19 pandemic, as well as to identify subgroups in which the influence of DM has higher impact on the clinical outcome.

\section{Methods}

\section{Study population}

We have previously published the outcome of patients in whom elective ICP were cancelled or postponed when the state of alarm due to the COVID-19 pandemic was declared in Spain on the 14th of March 2020. In this study, 2,158 patients were included in 37 hospitals [8].

At the time of the publication of that study, DM status was known in 2,110, whereas no information was available for 48 patients. For the present sub-study, doing additional efforts, directly contacting with the patient or obtaining documents from the referral centers, we could obtain DM status for all 2158 patients.

\section{Data collection and follow-up}

Data were entered in an electronic database (pInvestiga, Moaña, Pontevedra, Spain). Clinical variables, such as main cardiovascular disease pending on treatment, type of procedure pending to be performed, clinical situation, and cardiovascular risk factors, were collected.

Patients were followed-up until the 30th of April 2020 (45 days) [8]. Patients with DM were compared with those without DM, regarding type of pending procedure, main cardiovascular disease, functional class for heart failure and angina, and other clinical variables. The influence of DM in different patient subgroups was evaluated.

\section{Definitions}

Coronary angiography and/or PCI as the type of pending procedure included coronary angiography in patients with previously diagnosed or suspected CAD, and those with previously known CAD pending on PCI (e.g. stage procedures). Coronary angiography to rule out CAD as the underlying cause of left ventricular dysfunction was also included in this category. However, coronary angiography as part of the study of patients pending on any type of surgical intervention was included in a different category, because the main underlying condition was considered to be the disorder pending to be treated (e.g. valvular heart disease) rather than the eventual bystander of coronary artery disease. Other procedures included transcatheter aortic valve implantation (TAVI), percutaneous mitral valve repair, left atrial appendage closure, percutaneous closure of ASD, or treatment of tricuspid regurgitation.

\section{Statistical analysis}

Continuous variables are presented as mean \pm standard deviation and compared using the Student t-test or appropriate non-parametric tests. Discrete variables are presented as percentages (proportions), and compared with the Chi-square test, using Fisher correction when needed. Statistical analysis was done using the SPSS statistical package (Chicago, Illinois). Associations were considered statistically significant when $\mathrm{p}<0.05$, although all $p$ values are presented. Univariable and multivariable analysis were conducted in order to identify independent risk factors for mortality, and for secondary endpoints.

\section{Results}

\section{Type of pending procedure}

Out of the 2,158 patients, 700 (32.4\%) were DM. Figure 1 shows the type of pending procedure in patients with and without DM. Coronary diagnostic and/or therapeutic intervention was the most frequent pending procedure for both groups of patients, but it was more frequent in DM than in non-DM (61.5\% vs. $49.5 \%$, respectively; $\mathrm{p}<0.001$ ). The second type of procedure was percutaneous valvular intervention, that accounted for $17.9 \%$ and $16.2 \%$ for $\mathrm{DM}$ and non-DM, respectively $(\mathrm{p}=0.300)$. Other diagnostic procedure was pending in $14.2 \%$ and $25.2 \%$ of DM and non-DM patients, respectively $(\mathrm{p}<0.001)$. Other therapeutic procedure was pending in $6.7 \%$ and $9.1 \%$ in patients with and without $\mathrm{DM}$, respectively $(\mathrm{p}=0.060)$. 


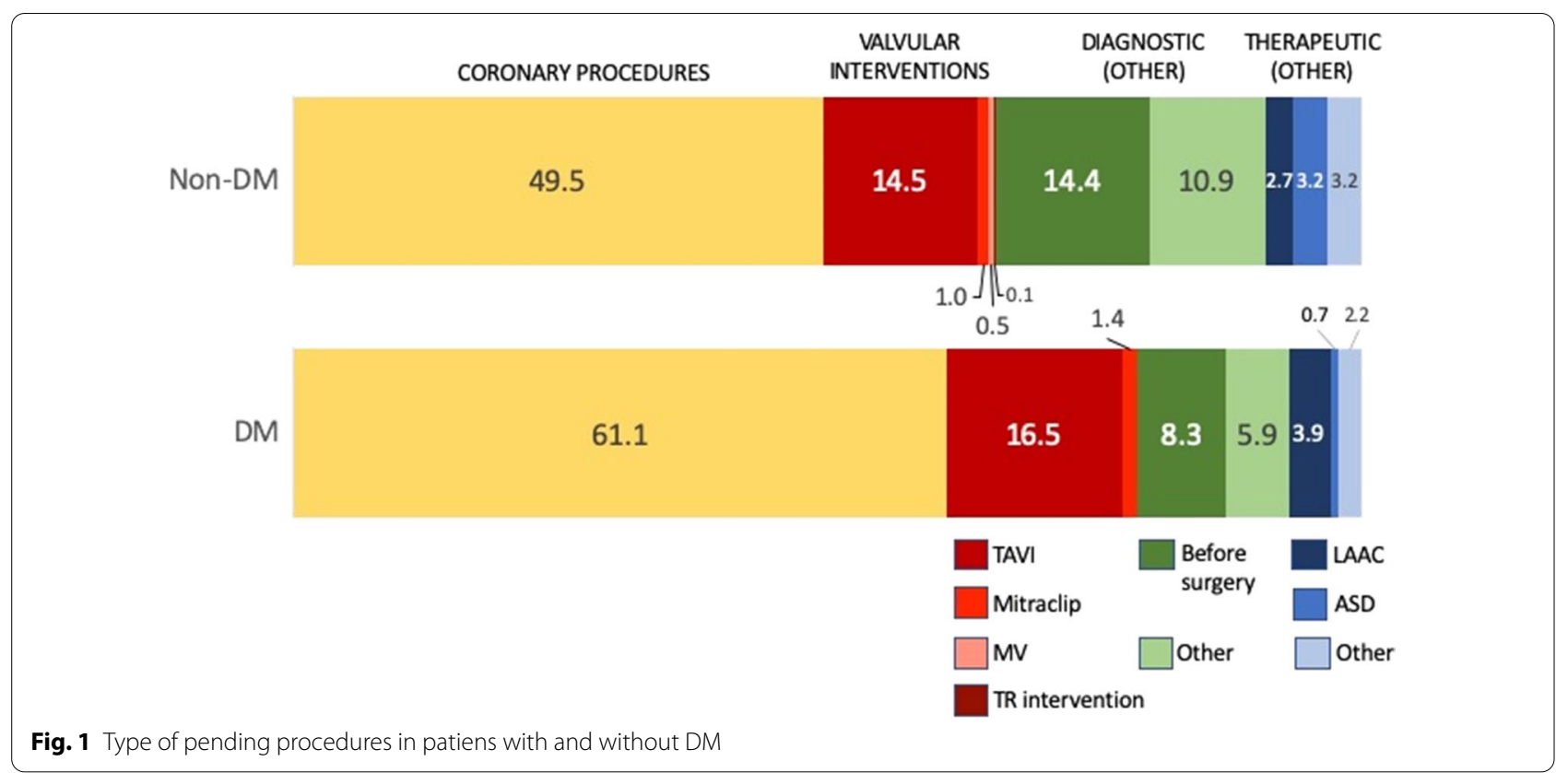

\section{Comparison of patients with and without DM}

Table 1 shows the differences among patients with and without DM in relation with clinical characteristics. Patients with DM were older, and had a higher prevalence of hypertension, hypercholesterolemia, chronic renal failure, peripheral artery disease, and previously diagnosed coronary artery disease including previous infarction, and previous myocardial revascularization. Left ventricular dysfunction was more frequently present in patients with DM. Functional class for heart failure (NYHA) was similar for patients with and without DM, but functional class for angina (CCS) was worse in patients with DM.

Among the 2,158 patients, 559 had previously documented coronary artery disease. Patients with DM had higher frequency of multi-vessel disease $(72.9 \%$ vs. $56.7 \%$ in non-DM, $\mathrm{p}<0.001)$. Left main disease was also more frequent in patients with DM, but differences were not statistically significant $(13.9 \%$ vs. $9.8 \%$ in non-DM, $\mathrm{p}=0.133)$.

\section{Influence of DM on clinical outcomes}

During the 45-day follow-up period, 36 patients died (1.7\%), most of them due to cardiovascular causes $(\mathrm{n}=19,59.4 \%)$. Patients with DM had a higher rate of both overall mortality ( $3.0 \%$ vs. $1.0 \%$ in non-DM, $\mathrm{p}=0.001)$ and cardiovascular mortality $(1.9 \%$ vs. $0.4 \%$ in non-DM, $\mathrm{p}=0.001$ ), whereas differences in non-cardiovascular mortality were not statistically different $(1.1 \%$ vs. $0.6 \%$ in DM and non-DM, respectively; $\mathrm{p}=0.196$ ).
Table 1 Clinical characteristics of patients with and without DM

\begin{tabular}{|c|c|c|c|}
\hline & \multicolumn{2}{|l|}{ DM } & \multirow[b]{2}{*}{$P$ value } \\
\hline & Yes $(n=700)$ & No $(n=1458)$ & \\
\hline Age & $72.3 \pm 10.0$ & $69.2 \pm 12.7$ & $<0.001$ \\
\hline Age $\geq 80(\%)$ & 24.9 & 21.4 & 0.078 \\
\hline Female gender (\%) & 34.9 & 39.9 & 0.066 \\
\hline Hypertension (\%) & 82.9 & 59.8 & $<0.001$ \\
\hline Hypercholesterolemia (\%) & 71.0 & 47.9 & $<0.001$ \\
\hline Smoking (\%) & 30.8 & 29.3 & 0.483 \\
\hline Chronic renal failure (\%) & 13.2 & 7.5 & $<0.001$ \\
\hline Peripheral artery disease (\%) & 14.2 & 9.0 & $<0.001$ \\
\hline Previous CAD (\%) & 41.7 & 27.4 & $<0.001$ \\
\hline Previous infarction (\%) & 17.9 & 11.4 & $<0.001$ \\
\hline Previous PCI (\%) & 23.6 & 15.5 & $<0.001$ \\
\hline Previous CABG (\%) & 6.7 & 3.4 & 0.001 \\
\hline Previous valve replacement (\%) & 3.5 & 4.9 & 0.144 \\
\hline Left ventricular dysfunction (\%) & 27.1 & 21.4 & 0.033 \\
\hline NYHA $>\|(\%)$ & 20.1 & 19.0 & 0.282 \\
\hline$C C S>\|(\%)$ & 10.0 & 8.4 & 0.001 \\
\hline \multicolumn{4}{|l|}{ Main cardiovascular condition (\%) } \\
\hline Ischemic heart disease & 57.6 & 47.0 & $<0.001$ \\
\hline Valvular heart disease & 29.2 & 36.9 & \\
\hline Other & 13.3 & 16.2 & \\
\hline
\end{tabular}

$C A D$ coronary artery disease, $P C I$ Percutaneous coronary intervention, $C A B G$ Coronary artery bypass grafting, NYHA New York Heart Association, CCS Cardiology Canadian Society 
In the multivariable analysis, DM remained as an independent risk factor both for overall and cardiovascular mortality (Fig. 2).

The proportion of patients that underwent an urgent procedure due to clinical instabilization was also significantly higher in patients with DM (10.4\% vs. $7.3 \%$ in non-DM; $\mathrm{p}=0.015$ ).

During the study period, 17 patients with DM (2.4\%) and 21 without DM (1.4\%) had a diagnosis of COVID19 by protein-chain reaction test for SARS-CoV-2 $(\mathrm{p}=0.157)$. Out of these patients, $11(29.7 \%)$ died. Among patients with COVID-19 disease, 16 were diabetics, and 21 non diabetics, mortality being higher in diabetics $(6 / 16 ; 37.5 \%)$ than in non diabetics $(5 / 21$; $23.8 \%)$, but difference was not statistically significant $(\mathrm{p}=0.475)$.
Mortality in patients with and without DM among different subgroups

Mortality and cardiovascular mortality were higher in patients with DM regardless the main cardiovascular disease, although differences were statistically significant only for those patients with valvular heart disease (Fig. 3a and $b$ ).

Figure 4 shows the mortality and cardiovascular mortality rates in patients with and without DM in the most frequent types of pending procedures. Mortality and cardiovascular mortality rates were higher in patients pending on coronary diagnostic or therapeutic procedures, TAVI, and other diagnostic procedures, but differences reached statistical significance only for cardiovascular mortality in patients pending on TAVI. In patients pending on LAAC, mortality was higher in non-DM but differences were not statistically different.

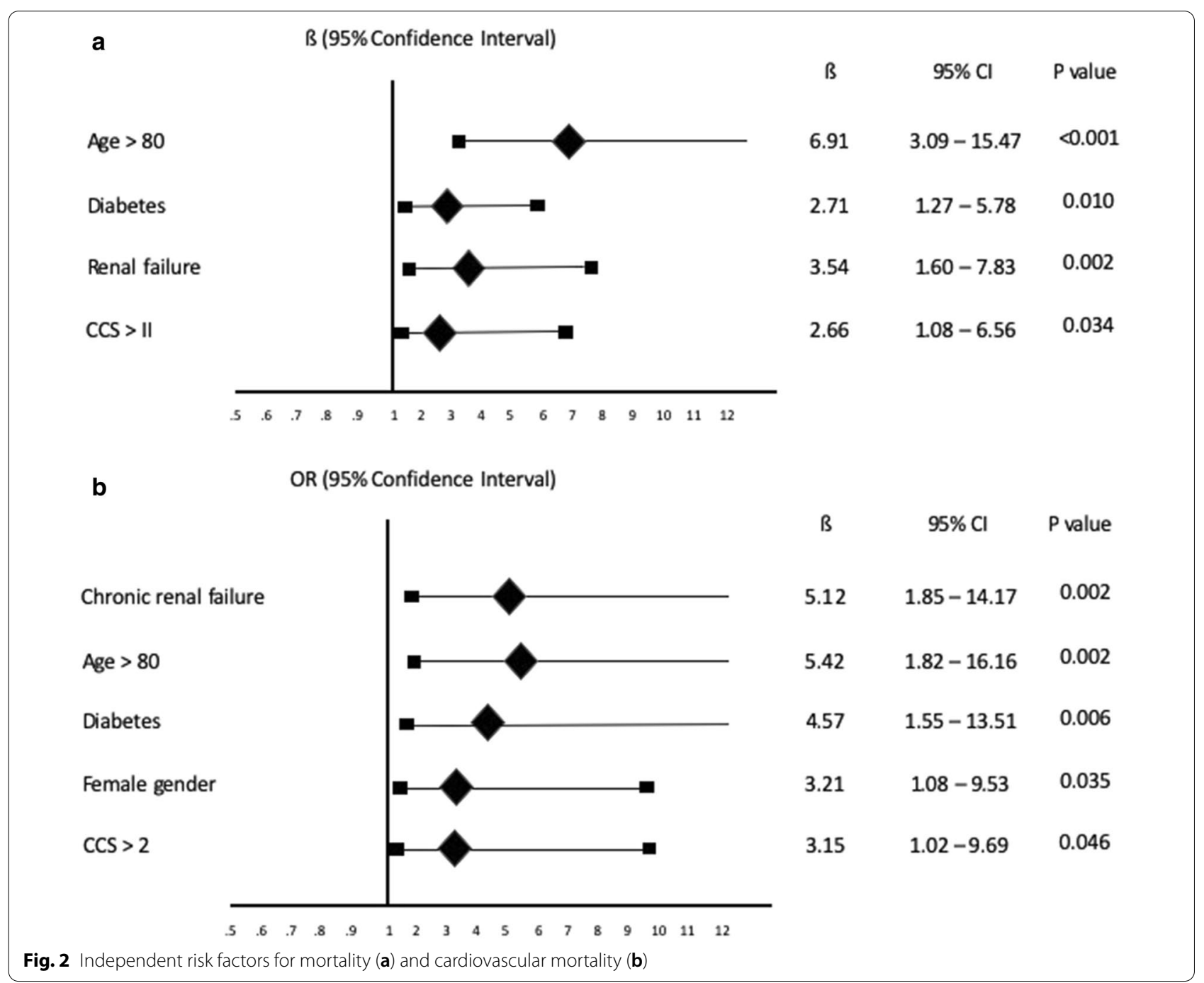


a

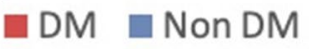

$p=0.155$

1.3

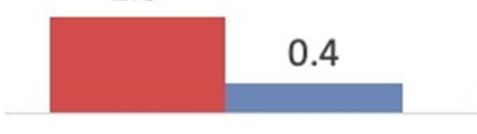

Ischemic heart disease

\section{b}

DM $=$ Non DM

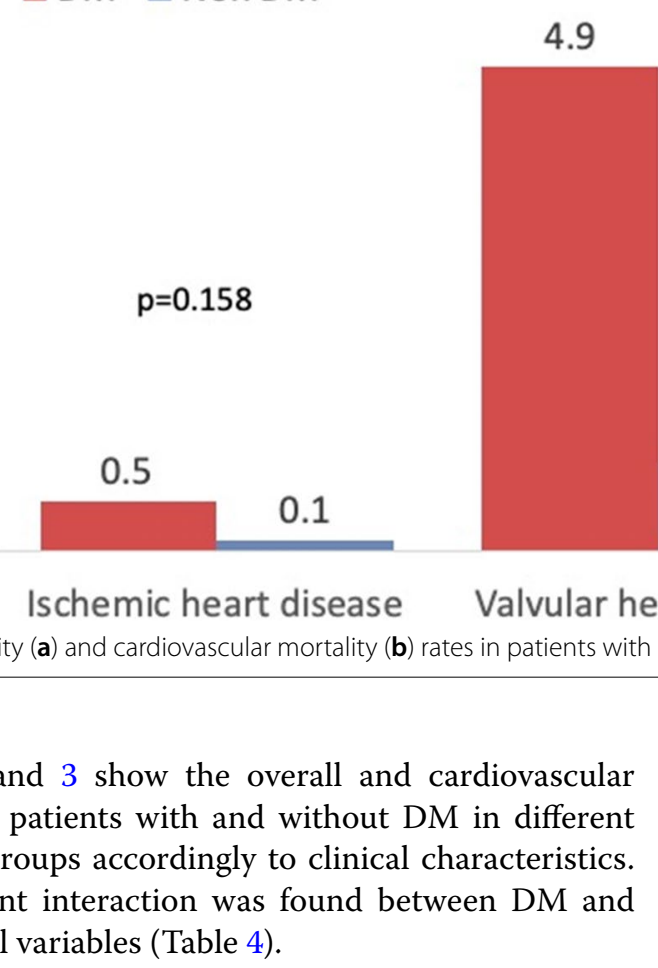

Tables 2 and 3 show the overall and cardiovascular mortality in patients with and without DM in different patient subgroups accordingly to clinical characteristics. No significant interaction was found between DM and other clinical variables (Table 4).

\section{Discussion}

Among patients in whom an elective cardiac invasive procedure was cancelled or postponed, those with DM had a significantly higher mortality, mainly due to a higher cardiovascular mortality. Overall mortality was 3 times higher and cardiovascular mortality 4.75 times higher in DM in comparison with patients without DM.
$P<0.001$

\section{9}

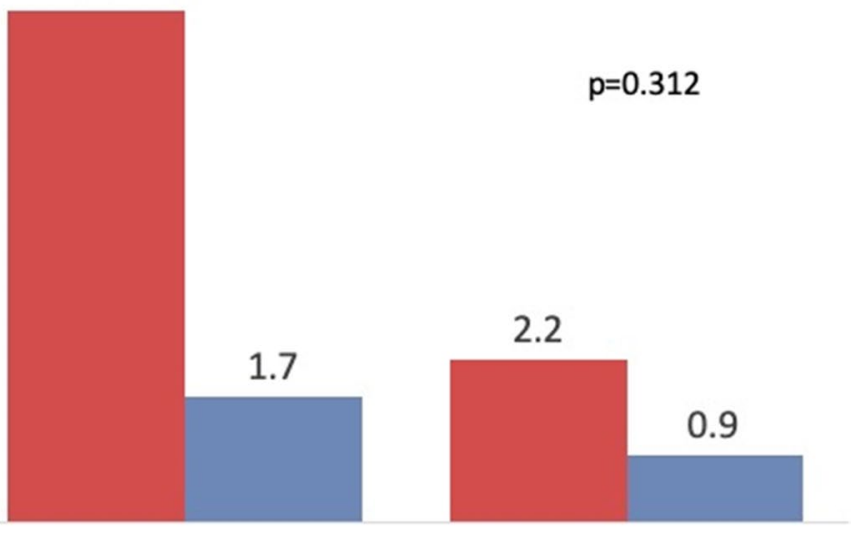

Other

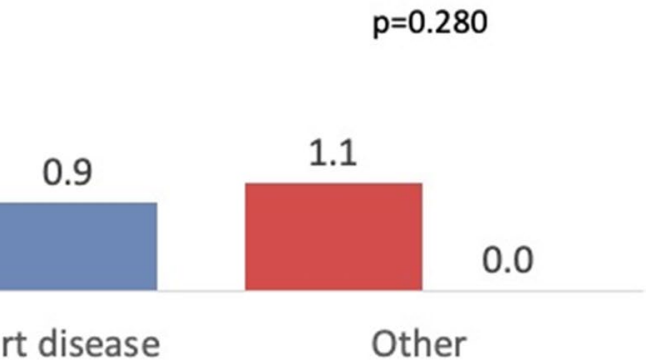

Fig. 3 Mortality (a) and cardiovascular mortality (b) rates in patients with and without DM accordingly to the main cardiovascular disease

Patients with DM had a worse clinical profile, including more advanced age, and higher prevalence of additional cardiovascular risk factors, previous cardiovascular diseases, and some co-morbidities, such as renal failure. However, DM was an independent predictor both for mortality and cardiovascular mortality, indicating that DM per se is a risk factor in this special population. The main practical implication of these findings is that elective invasive cardiac procedures should be prioritized in patients with DM. That is, during COVID-19 pandemic, invasive cardiac procedures should not be postponed in patients with DM. Even, this may be applicable not only during COVID-19 pandemic in particular [7], but also in other situations in which health care system cannot 

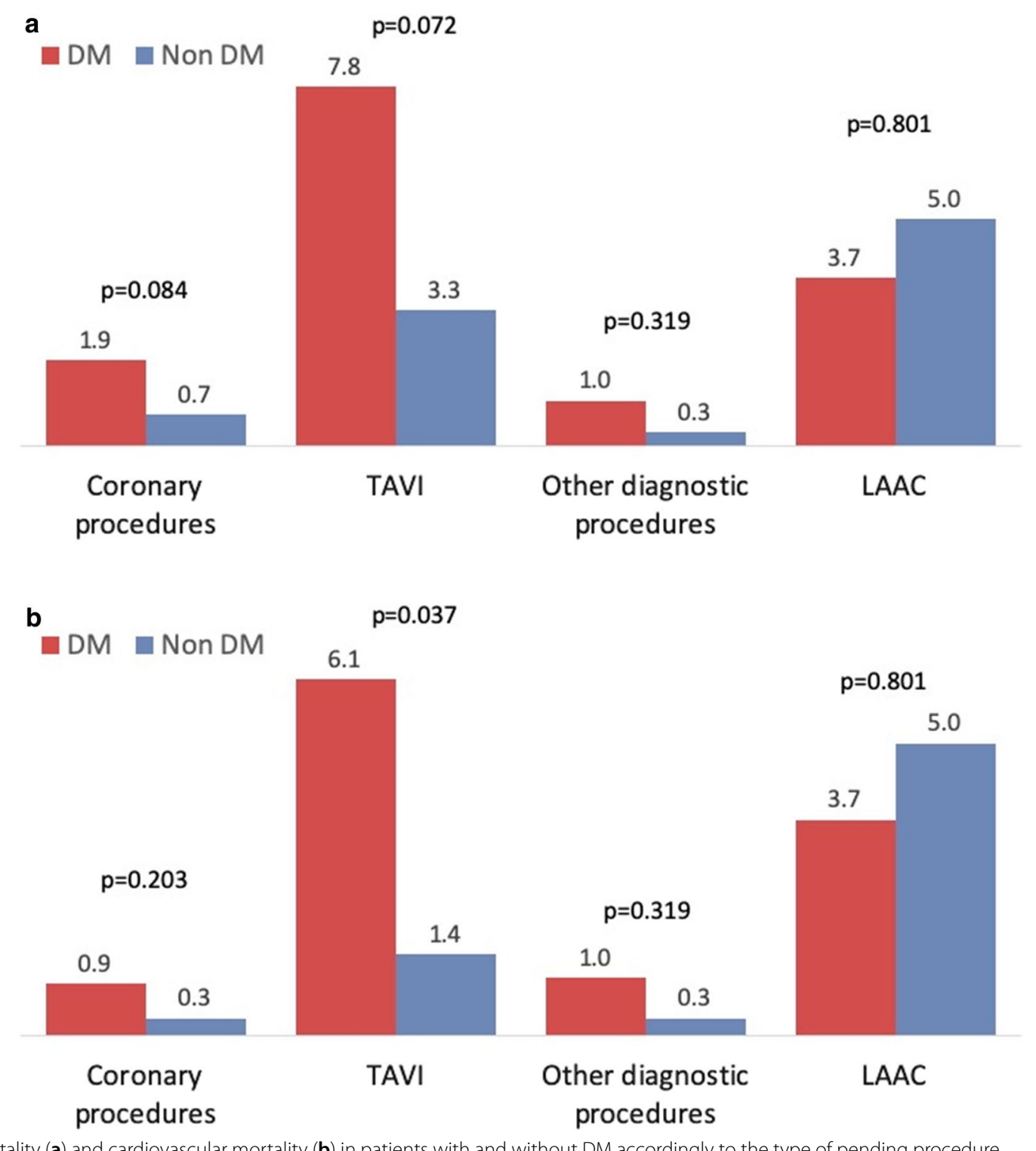

Fig. 4 Mortality (a) and cardiovascular mortality (b) in patients with and without DM accordingly to the type of pending procedure

adequately attend all patients pending on invasive procedures, and in waiting list management of interventional cardiology in general.

No significant interaction was found between DM and other clinical variables. This simplifies the indication of not cancelling ICP in patients with DM, because mortality and cardiovascular mortality was higher in patients with DM irrespectively on other clinical characteristics.

The worse outcome in patients with DM may have several reasons. First, DM is associated with an impaired systolic and diastolic left ventricular function in patients without significant coronary artery disease [13], and this could have a negative impact on the outcome of patients with heart failure or valvular heart disease. Second, DM patients have a procoagulant state [14] that may increase the risk of thromboembolic events in patients pending on structural interventions. Third, the response to anti-thrombotic agents is impaired in patients with DM [15], and this could have an impact on the risk of ischemic events in patients pending on coronary interventions. Fourth, coronary artery disease is more frequent and more severe in patients with DM and severe valvular disease [16], and this could have a negative prognostic impact on clinical outcome. Finally, DM predisposes to infections [18], that constitute an important cause 
Table 2 Mortality in patients with and without DM in different patients subgroups

\begin{tabular}{|c|c|c|c|c|c|c|}
\hline & \multicolumn{6}{|c|}{ Factor present } \\
\hline & \multicolumn{3}{|l|}{ Yes } & \multicolumn{3}{|l|}{ No } \\
\hline & $\mathrm{DM}$ & Non-DM & $P$ value & $\mathrm{DM}$ & Non-DM & $P$ value \\
\hline Age > $80(\%)$ & 7.5 & 3.8 & 0.071 & 1.5 & 0.3 & 0.006 \\
\hline Female gender (\%) & 5.0 & 1.2 & 0.001 & 2.0 & 0.9 & 0.098 \\
\hline Hypertension (\%) & 3.3 & 1.1 & 0.003 & 0.0 & 0.7 & 0.362 \\
\hline Hypercholesterolemia (\%) & 3.3 & 1.2 & 0.012 & 1.5 & 0.7 & 0.378 \\
\hline Smoking (\%) & 1.0 & 0.2 & 0.262 & 3.4 & 1.2 & 0.004 \\
\hline Chronic renal failure (\%) & 9.9 & 2.8 & 0.036 & 2.0 & 0.9 & 0.044 \\
\hline Peripheral artery disease (\%) & 3.1 & 3.1 & 1.000 & 3.0 & 0.8 & $<0.001$ \\
\hline Previous CAD (\%) & 2.4 & 1.8 & 0.537 & 3.0 & 0.7 & 0.001 \\
\hline Previous infarction (\%) & 2.4 & 0.6 & 0.314 & 3.1 & 1.1 & 0.002 \\
\hline Previous PCI (\%) & 2.4 & 0.4 & 0.165 & 3.2 & 1.1 & 0.003 \\
\hline Previous CABG (\%) & 0.0 & 6.3 & 0.242 & 3.2 & 0.9 & $<0.001$ \\
\hline Previous valve replacement (\%) & 4.3 & 1.5 & 0.444 & 2.6 & 0.8 & 0.002 \\
\hline Left ventricular dysfunction (\%) & 1.6 & 0.7 & 0.370 & 3.2 & 1.0 & 0.001 \\
\hline NYHA > $2(\%)$ & 7.1 & 2.5 & 0.061 & 2.1 & 0.7 & 0.014 \\
\hline CCS > $2(\%)$ & 4.8 & 3.9 & 1.000 & 2.7 & 0.7 & 0.001 \\
\hline
\end{tabular}

PC Percutaneous coronary intervention. CABG Coronary artery bypass grafting, NYHA New York Heart Association, CCS Cardiology Canadian Society

Table 3 Cardiovascular mortality in patients with and without DM in different patients subgroups

\begin{tabular}{|c|c|c|c|c|c|c|}
\hline & \multicolumn{6}{|c|}{ Factor present } \\
\hline & \multicolumn{3}{|l|}{ Yes } & \multicolumn{3}{|l|}{ No } \\
\hline & $\mathrm{DM}$ & Non-DM & P value & $\mathrm{DM}$ & Non-DM & P value \\
\hline Age $>80(\%)$ & 4.6 & 1.9 & 0.093 & 1.0 & 0.0 & 0.003 \\
\hline Female gender (\%) & 4.1 & 0.5 & 0.001 & 0.7 & 0.3 & 0.409 \\
\hline Hypertension (\%) & 2.3 & 0.5 & 0.002 & 0.0 & 0.2 & 1.000 \\
\hline Hypercholesterolemia (\%) & 2.0 & 0.6 & 0.023 & 1.5 & 0.1 & 0.032 \\
\hline Smoking (\%) & 0.5 & 0.0 & 0.335 & 2.3 & 0.5 & 0.002 \\
\hline Chronic renal failure (\%) & 7.7 & 1.9 & 0.083 & 1.0 & 0.3 & 0.079 \\
\hline Peripheral artery disease (\%) & 0.0 & 0.0 & 1.000 & 2.2 & 0.5 & $<0.001$ \\
\hline Previous CAD (\%) & 1.4 & 0.5 & 0.244 & 2.3 & 0.4 & 0.002 \\
\hline Previous infarction (\%) & 0.8 & 0.6 & 1.000 & 2.1 & 0.4 & $<0.001$ \\
\hline Previous PCI (\%) & 1.8 & 0.4 & 0.312 & 1.9 & 0.4 & 0.004 \\
\hline Previous CABG (\%) & 0.0 & 2.1 & 1.000 & 2.0 & 0.4 & $<0.001$ \\
\hline Previous valve replacement (\%) & 4.3 & 0.0 & 0.253 & 1.7 & 0.4 & 0.002 \\
\hline Left ventricular dysfunction (\%) & 1.1 & 0.7 & 0.635 & 2.2 & 0.4 & 0.001 \\
\hline NYHA > 2 (\%) & 5.1 & 1.2 & 0.049 & 1.6 & 0.2 & 0.004 \\
\hline $\mathrm{CCS}>2(\%)$ & 3.2 & 2.9 & 1.000 & 1.8 & 0.2 & $<0.001$ \\
\hline
\end{tabular}

PCI Percutaneous coronary intervention, CABG Coronary artery bypass grafting, NYHA New York Heart Association, CCS Cardiology Canadian Society

of non-cardiovascular death in elderly cardiovascular patients $[19,20]$.

DM had a negative impact on mortality in all type of pending ICP. DM is associated with more severe coronary stenosis [17], and is a very well known risk factor for mortality in patients with CAD $[11,12]$.

Among patients with aortic stenosis, those with DM have a higher mortality rate [21]. This may be partly 
Table 4 Interaction between different variables and the effect of diabetes on mortality and cardiovascular mortality

\begin{tabular}{lll}
\hline & \multicolumn{2}{l}{ P for interaction } \\
\cline { 2 - 3 } & Mortality & $\begin{array}{l}\text { Cardiovascular } \\
\text { mortality }\end{array}$ \\
\hline Age > 80 (\%) & 0.192 & 0.990 \\
Female gender (\%) & 0.353 & 0176 \\
Hypertension (\%) & 0.996 & 0.996 \\
Hypercholesterolemia (\%) & 0.774 & 0.375 \\
Smoking (\%) & 0.799 & 0.994 \\
Chronic renal failure (\%) & 0.499 & 0.790 \\
Peripheral artery disease (\%) & 0.128 & 1.000 \\
Previous CAD (\%) & 0.102 & 0.478 \\
Previous infarction (\%) & 0.774 & 0.361 \\
Previous PCI (\%) & 0.550 & 0.950 \\
Previous CABG (\%) & & \\
Previous valve replacement (\%) & 0.976 & 0.997 \\
Left ventricular dysfunction (\%) & & \\
NYHA > 2 (\%) & 0.953 & 0.561 \\
CCS > 2 (\%) & 0.212 & 0.066 \\
\hline
\end{tabular}

explained by the higher frequency of some co-morbidities (e.g. renal insufficiency) and CAD [16], but DM also might have a direct effect on prognosis of these patients. Among patients with aortic stenosis, those with DM have a more impaired myocardial function and more severe hypertrophy [22]. In patients with aortic valve sclerosis, insulin resistance is a powerful independent predictor of subclinical left ventricular dysfunction regardless of concomitant visceral obesity and left ventricular hypertrophy [23]. Additionally, DM impairs coronary microvascular function in asymptomatic patients with severe aortic and non-obstructed coronary arteries [24]. Besides these potential explanations, cardiac mortality rate was unexpectedly high in DM patients awaiting a valvular procedure during a relatively short follow-up (45 days), and this novel finding warrants further research.

Other procedures apart from coronary and valvular interventions had also higher mortality in patients with DM. DM is a risk factor for mortality in patients on atrial fibrillation [25], and thus it is not surprising that among patients pending on LAAC, mortality was higher in diabetics.

\section{Study limitations}

This study has several limitations. First, the main goal of this study was to evaluate the short-term consequences of delaying or postponing invasive cardiac procedures. Because of that, clinical follow-up was restricted to only 45 days. Second, metabolic control, treatment of diabetes and type of diabetes were not collected, and therefore the potential influence of these factors could not be evaluated. Finally, some patients underwent an emergent procedure due to clinical instabilization. As this occurred more frequently in patients with DM, the influence of DM on mortality in our population even may have been underestimated.

\section{Conclusion}

Among patients in whom an elective invasive cardiac procedure is cancelled or postponed, those with DM have an especial worse clinical outcome, with higher mortality and cardiovascular mortality rates at shortterm, irrespective on other clinical conditions. Elective invasive cardiac procedures should be prioritized in patients with diabetes.

\begin{abstract}
Abbreviations
ASD: Atrial Septal Defect; CABG: Coronary Artery Bypass Grafting; CAD: Coronary Artery Disease; CCS: Canadian Cardiac Society; COVID-19: COronaVIrus Disease 2019; DM: Diabetes; ICP: Invasive Cardiac Procedures; LAAC: Left Atrial Appendage Closure; NYHA: New York Heart Association; PCl: Percutaneous Coronary Intervention; SARS-CoV-2: Severe Acute Respiratory Syndrome CoronaVirus 2; TAVI: Transcatheter aortic valve implantation.
\end{abstract}

\section{Acknowledgements \\ Not applicable.}

\section{Authors' contributions}

all authors have approved the submitted versión of the manuscript, and have agreed both to be personally accountable for the author's own contributions and to ensure that questions related to the accuracy or integrity of any part of the work, even ones in which the author was not personally involved, are appropriately investigated, resolved, and the resolution documented in the literature.Each author contribution is detailed below: Substantial contributions to the conception: RM, JAD, JAB, APP, FS, AGB, VRQ, FJI, BGB, MV, Design of the work: RM, JLD, RT, IAS, RR, SO, ICG, JM, SMBP,.Acquisition, analysis, and interpretation of data: RM, PS, JAC, PP, JJM, AF, EP. Drafted the work or substantively revised it: RM, JMTH, JFD, BV, DMS, FA, EB, EP, JRRA, FL, JRR, EN, EAB, RL. All authors read and approved the final manuscript.

\section{Funding}

Funding for data collection and analysis: Association of Interventional Cardiology of the Spanish Society of Cardiology (ACI-SEC). No funding was used for interpretation of data or manuscript writing.

\section{Availability of data and materials}

The datasets during and/or analysed during the current study available from the corresponding author on reasonable request.

\section{Declarations}

Ethics approval and consent to participate

Since this work was done during acute phase of COVID-19 pandemic, involving aspects related with the pandemic, ethics committee aproval was not required.

\section{Consent for publication}

Not applicable.

\section{Competing interests}

The authors declare that they have no competing interests. 


\begin{abstract}
Author details
${ }^{1}$ University Hospital La Paz, idiPAZ, Paseo La Castellana 261, 28046 Madrid, Spain. ${ }^{2}$ Hospital La Fe, Valencia, Spain. ${ }^{3}$ Hospital Miguel Servet, Zaragoza, Spain. ${ }^{4}$ Hospital Clínico San Carlos, Madrid, Spain. ${ }^{5}$ Hospital Universitario Marqués de Valdecilla, IDIVAL, Santander, Spain. ${ }^{6}$ Hospital German Trias I Pujol, Badalona, Spain. ${ }^{7}$ Hospital Clínico Universitario, Santiago de Compostela, Spain. ${ }^{8}$ Hospital Virgen de La Victoria, Málaga, Spain. ${ }^{9}$ Hospital Clínico Universitario, Valladolid, Spain. ${ }^{10}$ Hospital de Bellvitge, Barcelona, Spain. ${ }^{11}$ Hospital Juan Ramón Jiménez, Huelva, Spain. ${ }^{12}$ Hospital del Mar, Barcelona, Spain. ${ }^{13}$ Hospital Reina Sofía, Córdoba, Spain. ${ }^{14}$ Hospital Universitario de Salamanca, IBSAL, CIBER CV, Salamanca, Spain. ${ }^{15}$ Hospital de Cabueñes, Gijón, Spain. ${ }^{16}$ Complejo Hospitalario, León, Spain. ${ }^{17}$ Hospital Doce de Octubre, Madrid, Spain. ${ }^{18}$ Hospital San Pedro de La Rioja, Logroño, Spain. ${ }^{19}$ Hospital Puerta del Mar, Cádiz, Spain. ${ }^{20}$ Hospital de La Princesa, Madrid, Spain. ${ }^{21}$ Corporació Sanitaria Parc Tauli, Sabadell, Spain. ${ }^{22}$ Hospital Virgen de L'Arrixaca, Murcia, Spain. ${ }^{23}$ Hospital Lozano Blesa, Zaragoza, Spain. ${ }^{24}$ Hospital Clínico de Navarra, Pamplona, Spain. ${ }^{25}$ Hospital Universitario, Albacete, Spain. ${ }^{26}$ Hospital General Universitario, Ciudad Real, Spain. ${ }^{27}$ Hospital de Galdakao, Bilbao, Spain. ${ }^{28}$ Hospital Universitario, Guadalajara, Spain. ${ }^{29}$ Policlínica de Guipúzcoa, San Sebastian, Spain. ${ }^{30}$ Hospital Vall D'Hebron, Barcelona, Spain. ${ }^{31}$ Hospital Virgen de La Salud, Toledo, Spain. ${ }^{32}$ Hospital de Valme, Sevilla, Spain. ${ }^{33}$ Hospital San Juan, Alicante, Spain. ${ }^{34}$ Hospital Virgen del Rocío, Sevilla, Spain. ${ }^{35}$ Hospital Universitario de Torrejón, Universidad Francisco Vitoria, Torrejón de Ardoz, Spain. ${ }^{36}$ Hospital Ruber Internacional, Madrid, Spain. ${ }^{37}$ Hospital de Torrecárdenas, Almería, Spain. ${ }^{38}$ plnvestiga, Moaña, Pontevedra, Spain.
\end{abstract}

Received: 13 February 2021 Accepted: 13 March 2021 Published online: 23 March 2021

\section{References}

1. World Health Organization. Coronavirus disease 2019 (COVID-19) Situation Report - 78. Geneva: WHO; 2020. World Health Organization. Coronavirus disease. (COVID-19) Situation Report - 78. Geneva: WHO; 2019. p. 2020.

2. Rodríguez-Leor O, Cid-Álvarez B, Ojeda S, Martín-Moreiras J, Rumoroso JR, López-Palop R, et al. On behalf of all the participants of the ACI-SEC Infarction Code Registry Impact of the COVID-19 pandemic on interventional cardiology activity in Spain. Interv Cardiol. 2020;2:82-9.

3. Romaguera R, Cruz-González I, Jurado-Román A, Ojeda S, FernándezCisnal A, Jorge-Pérez $P$, et al. Considerations on the invasive management of ischemic and structural heart disease during the COVID-19 coronavirus outbreak. Consensus statement of the Interventional Cardiology Association and the Ischemic Heart Disease and Acute Cardiac Care Association of the Spanish Society of Cardiology. REC Interv Cardiol. 2020;2:106-11.

4. Rodríguez-Leor O, Cid-Álvarez B, de Prado A, Rossello X, Ojeda S, Serrador A, López-Palop R, Martín-Moreiras J, et al. Impact of COVID-19 on ST-segment elevation myocardial infarction care The Spanish experience. Rev Esp Cardiol. 2020;73:994-1002.

5. Chieffo A, Stefanini GG, Price S, Barbato E, Tarantini G, Karam N, Moreno R, Buchanan GL, Gilard M, Halvorsen S, Huber K, James S, Neumann FJ, Möllmann H, Roffi M, Tavazzi G, Mauri Ferré J, Windecker S, Dudek D, Baumbach A. EAPCI Position Statement on Invasive Management of Acute Coronary Syndromes during the COVID-19 pandemic. Eur Heart J. 2020:41:1839-51.

6. De Luca G, Verdoia M, Cercek M, Jensen LO, Vavlukis M, Calmac L, Johnson T, Ferrer GR, Ganyukov V, Wojakowski W, et al. Impact of COVID-19 pandemic on mechanical reperfusion for patients with STEMI. J Am Coll Cardiol. 2020;76:2321-30.

7. Chieffo A, Tarantini G, Naber CK, Barbato E, Roffi M, Stefanini GG, Buchanan GL, Buszman P, Moreno R, Zawiślak B, Cayla G, Danenberg H, Da Silveira JAB, Nef H, James SK, Mauri Ferre J, Voskuil M, Witt N, Windecker S, Baumbach A, Dudek D. Performing elective cardiac invasive procedures during the COVID-19 outbreak: a position statement from the European Association of Percutaneous Cardiovascular Interventions (EAPCI). Eur Heart J. 2020:41:1839-51.

8. Moreno R, Ojeda S, Romaguera R, Jimenez-Quevedo P, Cruz-González I. Transcatheter aortic valve replacement during COVID-19 pandemic Recommendations from the Association of Interventional Cardiology of the Spanish Society of Cardiology (ACI-SEC). REC: Interv Cardiol 2020;2:230-231.

9. Moreno R, Díez JL, Diarte JA, Macaya F, et al Consequences of canceling elective invasive cardiac procedures during Covid-19 outbreak. Catheter Cardiovasc Interv. 2020.Doi: https://doi.org/10.1002/ccd. 29433 (Epub ahead of print).

10. Einarson TR, Acs A, Ludwig C, Panton UH. Prevalence of cardiovascular disease in type 2 diabetes: a systematic literature review of scientific evidence from across the world in 2007-2017. Cardiovasc Diabetol. 2018;17:83

11. Malmberg K, Yusuf S, Gerstein HC, Brown J, Zhao F, Hunt D, Piegas L, Calvin J, Keltai M, Budaj A. Impact of diabetes on long-term prognosis in patients with unstable angina and non-Q-wave myocardial infarction: results of the OASIS (Organization to Assess Strategies for Ischemic Syndromes) Registry. Circulation. 2000;102:1014-9.

12. Moreno R, de Sa E, Lopez-Sendon JL, Ortega A, Fernández MJ, Fernandez-Bobadilla J, et al. Prognosis of medically stabilized unstable angina pectoris with a negative exercise test. Am J Cardiol. 1998;82:662-5.

13. Andersson C, Gislason GH, Weeke P, Hoffmann S, Hansen PR, TorpPedersen C, Søgaard P. Diabetes is associated with impaired myocardial performance in patients without significant coronary artery disease. Cardiovasc Diabetol. 2010;9:3.

14. Jax TW, Peters AJ, Plehn G, Schoebel FC. Hemostatic risk factors in patients with coronary artery disease and type 2 diabetes - a two year follow-up of 243 patients. Cardiovasc Diabetol. 2009;8:48.

15. Angiolillo DJ, Bernardo E, Sabaté M, Jimenez-Quevedo P, Costa MA, Palazuelos J, Hernández-Antolin R, Moreno R, Escaned J, Alfonso F, Bañuelos C, Guzman LA, Bass TA, Macaya C, Fernandez-Ortiz A. Impact of platelet reactivity on cardiovascular outcomes in patients with type 2 diabetes mellitus and coronary artery disease. J Am Coll Cardiol. 2007:50:1541-7.

16. Lappé JM, Grodin JL, Wu Y, Bott-Silverman C, Cho L. Prevalence and prediction of obstructive coronary artery disease in patients referred for valvular heart surgery. Am J Cardiol. 2015;116:280-5.

17. Chu ZG, Yang ZG, Dong ZH, Zhu ZY, Peng LQ, Shao H, He C, Deng W, Tang SS, Chen J. Characteristics of coronary artery disease in symptomatic type 2 diabetic patients: evaluation with CT angiography. Cardiovasc Diabetol. 2010;9:74.

18. Moutschen MP, Scheen AJ, Lefebvre PJ. Impaired immune responses in diabetes mellitus: analysis of the factors and mechanisms involved Relevance to the increased susceptibility of diabetic patients to specific infections. Diabete Metab. 1992;18:187-201.

19. Moreno R, Calvo L, Salinas P, Dobarro D, Santiago JV, Sanchez A, Galeote G, Riera L, Moreno-Gomez I, Mesa J, Plaza I, Lopez-Sendon J. Causes of peri-operative mortality after transcatheter aortic valve implantation: a pooled analysis of 12 studies and 1223 patients. J Invasive Cardiol. 2011;23:180-4.

20. Aschauer S, Zotter-Tufaro C, Duca F, Kammerlander A, Dalos D, Mascherbauer J, Bonderman D. Modes of death in patients with heart failure and preserved ejection fraction. Int J Cardiol. 2017;228:422-6.

21. Lancellotti P, Magne J, Dulgheru R, Clavel MA, Donal E, Vannan MA, Chambers J, Rosenhek R, Habib G, Lloyd G, Nistri S, Garbi M, Marchetta S, Fattouch K, Coisne A, Montaigne D, Modine T, Davin L, Gach O, Radermecker M, Liu S, Gillam L, Rossi A, Galli E, Ilardi F, Tastet L, Capoulade R, Zilberszac R, Vollema EM, Delgado V, Cosyns B, Lafitte S, Bernard A, Pierard LA, Bax JJ, Pibarot P, Oury C. Outcomes of Patients With Asymptomatic Aortic Stenosis Followed Up in Heart Valve Clinics. JAMA Cardiol. 2018;3:1060-8.

22. Pagé A, Dumesnil JG, Clavel MA, Chan KL, Teo KK, Tam JW, Mathieu P, Després JP, Pibarot P; ASTRONOMER Investigators. Metabolic syndrome is associated with more pronounced impairment of left ventricle geometry and function in patients with calcific aortic stenosis: a substudy of the ASTRONOMER (Aortic Stenosis Progression Observation Measuring Effects of Rosuvastatin). J Am Coll Cardiol. 2010;55:1867-74.

23. Utsunomiya H, Yamamoto H, Kunita E, Hidaka T, Kihara Y. Insulin resistance and subclinical abnormalities of global and regional left ventricular function in patients with aortic valve sclerosis. Cardiovasc Diabetol. 2014;13:86.

24. Julius BK, Spillmann M, Vassalli G, Villari B, Eberli FR, Hess OM. Angina pectoris in patients with aortic stenosis and normal coronary arteries. Mech Pathophysiol Concepts Circ. 1997;95:892-8. 
25. Bassand JP, Virdone $S$, Goldhaber SZ, Camm AJ, Fitzmaurice DA, Fox KAA, Goto S, Haas S, Hacke W, Kayani G, Mantovani LG, Misselwitz F, Pieper KS, Turpie AGG, van Eickels M, Verheugt FWA, Kakkar AK. Early risks of death, stroke/systemic embolism, and major bleeding in patients with newly diagnosed atrial fibrillation. Circulation. 2019;139:787-98.

\section{Publisher's Note}

Springer Nature remains neutral with regard to jurisdictional claims in published maps and institutional affiliations.
Ready to submit your research? Choose BMC and benefit from:

- fast, convenient online submission

- thorough peer review by experienced researchers in your field

- rapid publication on acceptance

- support for research data, including large and complex data types

- gold Open Access which fosters wider collaboration and increased citations

- maximum visibility for your research: over 100M website views per year

At BMC, research is always in progress.

Learn more biomedcentral.com/submissions 